\title{
Abuse, self-harm and suicidal ideation in the UK during the COVID-19 pandemic
}

Eleonora Iob, Andrew Steptoe and Daisy Fancourt

\section{Summary}

This study explored patterns of abuse, self-harm and thoughts of suicide/self-harm in the UK during the first month of the COVID-19 pandemic using data from the COVID-19 Social Study ( $n=44775)$, a non-probability sample weighted to population proportions. The reported frequency of abuse, self-harm and thoughts of suicide/self-harm was higher among women, Black, Asian and minority ethnic (BAME) groups and people experiencing socioeconomic disadvantage, unemployment, disability, chronic physical illnesses, mental disorders and COVID-19 diagnosis. Psychiatric medications were the most common type of support being used, but fewer than half of those affected were accessing formal or informal support.

\section{Keywords}

COVID-19; mental health; abuse; self-harm; thoughts of suicide or self-harm

\section{Copyright and usage}

(c) The Author(s), 2020. Published by Cambridge University Press on behalf of the Royal College of Psychiatrists. This is an Open Access article, distributed under the terms of the Creative Commons Attribution licence (http://creativecommons.org/ licenses/by/4.0/), which permits unrestricted re-use, distribution, and reproduction in any medium, provided the original work is properly cited.
The COVID-19 pandemic is presenting an unprecedented global challenge not just for infectious disease medicine but also for mental healthcare. Concerns about the psychological, social and neurological impact of the disease have been reported, ${ }^{1}$ along with preliminary data suggesting adverse effects on a range of aspects of mental health, including anxiety and depression. ${ }^{2}$

Self-harm, suicidal thoughts and abuse are already substantial problems in the UK. The prevalence of life-time experience of self-harming was reported to be $6.4 \%$ in $2014{ }^{3}$ prevalence of lifetime thoughts of suicide was around $20.6 \%$, with $5.4 \%$ reporting such thoughts in the previous year; ${ }^{4}$ and $7.5 \%$ of women and $3.8 \%$ of men reported experiencing abuse from a partner or family member in the year ending March $2019 .{ }^{5}$ But there have been rising concerns about people experiencing higher levels of psychological or physical abuse while social distancing at home during the COVID-19 pandemic, alongside increases in selfharming or suicidal ideation. Staying at home because of social distancing measures could increase the exposure of individuals to violence and abuse. ${ }^{6}$ Economic adversity and unemployment could lead to additional stress for individuals, especially disadvantaged and vulnerable groups. ${ }^{7,8}$ Individuals may be unable to access usual social networks that could provide support and may experience increased loneliness and isolation. Additionally, pressures on health services have led to disruptions to existing mental health services and reductions in use by individuals. ${ }^{7}$ All of these factors are linked with higher rates of self-harm, suicide and poor mental health outcomes. ${ }^{9,10}$

Already, some helplines have reported increases in the volume of calls since lockdown began and other data also suggest an increase in abuse-related incidents. ${ }^{7}$ However, data about the characteristics of people reporting such experiences in the UK during the COVID-19 pandemic are still scarce. Further, it is unclear whether people experiencing abuse and self-harming are managing to access any support. This is vital to understand in order to identify what further support is needed. Therefore, this study sought to address these evidence gaps by exploring patterns of abuse, self-harm and thoughts of suicide or self-harm in the UK in the first month of lockdown due the COVID-19 pandemic and exploring whether those having such experiences were accessing formal or informal mental health support.

\section{Method}

We used data from University College London's (UCL's) COVID-19 Social Study, a large longitudinal study on the psychological and social experiences of over 50000 adults in the UK during the pandemic. The study began on 21 March 2020, involving online questionnaires completed by participants on a weekly basis. For this analysis, we focused on participants recruited between 21 March and 20 April 2020. From a total sample of 55481 individuals, we included those who provided data on abuse, self-harm and thoughts of suicide or self-harm on at least one occasion $(n=44775)$. The sample was well-stratified across sociodemographic characteristics and all data were weighted to the proportions of gender, age, ethnicity, education and country of living obtained from the Office for National Statistics ${ }^{11}$ (see supplementary material available at https://doi.org/10.1192/bjp.2020.130 for further details on the sample and methods).

Thoughts of suicide or self-harm were assessed using the final item of the Patient Health Questionnaire (PHQ-9) (experiencing 'thoughts that you would be better off dead or of hurting yourself in some way'). Self-harm was measured by asking participants if they had been 'self-harming or deliberately hurting'. Physical abuse was measured by asking participants if they had been 'physically harmed or hurt by someone else'. Psychological abuse was measured by asking if participants had been 'bullied, controlled, intimidated, or psychologically hurt by someone else'. All responses were about the previous week and measured on a four-point scale from 'not at all' to 'nearly every day'. For the analysis, we focused on any response that indicated any experience of self-harm or abuse on at least one occasion during the first month of lockdown.

Ethical approval for the COVID-19 Social Study was granted by the UCL Ethics Committee. All participants provided fully informed consent. The study is GDPR compliant.

\section{Results}

Overall, 4121 participants (9\%) surveyed reported experiencing psychological or physical abuse, 7984 participants (18\%) reported experiencing thoughts of suicide or self-harm in the first month of lockdown and 2174 participants (5\%) reported harming 
Table 1 Weighted sample characteristics (a) and mental health support strategies (b)

\begin{tabular}{|c|c|c|c|c|c|}
\hline & Total & $\begin{array}{l}\text { Psychological } \\
\text { abuse }\end{array}$ & $\begin{array}{l}\text { Physical } \\
\text { abuse }\end{array}$ & $\begin{array}{l}\text { Self-harm/suicidal } \\
\text { thoughts }\end{array}$ & $\begin{array}{l}\text { Self-harm } \\
\text { behaviours }\end{array}$ \\
\hline (a) Sample characteristics & $N=44775$ & $N=3736$ & $N=1317$ & $N=7984$ & $N=2174$ \\
\hline \multicolumn{6}{|l|}{ Gender } \\
\hline Female & 22846 (51.0\%) & $2130(9.3 \%)$ & $530(2.3 \%)$ & 4099 (17.9\%) & 1205 (5.3\%) \\
\hline Male & 21929 (49.0\%) & 1605 (7.3\%) & $787(3.6 \%)$ & 3885 (17.7\%) & $970(4.4 \%)$ \\
\hline \multicolumn{6}{|l|}{ Age, years } \\
\hline $18-29$ & 7835 (17.5\%) & $768(9.8 \%)$ & $304(3.9 \%)$ & $2270(29.0 \%)$ & $748(9.6 \%)$ \\
\hline 30-44 & 10394 (23.2\%) & $960(9.2 \%)$ & $325(3.1 \%)$ & $2102(20.2 \%)$ & $541(5.2 \%)$ \\
\hline $45-59$ & $12031(26.9 \%)$ & $1106(9.2 \%)$ & $351(2.9 \%)$ & $2073(17.2 \%)$ & $549(4.6 \%)$ \\
\hline $60+$ & 14515 (32.4\%) & $902(6.2 \%)$ & $337(2.3 \%)$ & $1540(10.6 \%)$ & $336(2.3 \%)$ \\
\hline \multicolumn{6}{|l|}{ Ethnicity } \\
\hline BAME groups & 5259 (11.7\%) & $656(12.5 \%)$ & $226(4.3 \%)$ & $1243(23.6 \%)$ & $401(7.6 \%)$ \\
\hline White & 39516 (88.3\%) & $3080(7.8 \%)$ & $1091(2.8 \%)$ & $6741(17.1 \%)$ & $1773(4.5 \%)$ \\
\hline \multicolumn{6}{|l|}{ Marital status } \\
\hline Living alone & 9375 (20.9\%) & 878 (9.4\%) & $344(3.7 \%)$ & $2208(23.6 \%)$ & $596(6.4 \%)$ \\
\hline $\begin{array}{l}\text { Not living with partner/spouse but living with } \\
\text { another adult }\end{array}$ & $9131(20.4 \%)$ & $1072(11.7 \%)$ & $442(4.8 \%)$ & $2528(27.7 \%)$ & $823(9.0 \%)$ \\
\hline Living with partner/spouse & $26269(58.7 \%)$ & $1785(6.8 \%)$ & $531(2.0 \%)$ & $3248(12.4 \%)$ & $756(2.9 \%)$ \\
\hline \multicolumn{6}{|l|}{ Children in the household } \\
\hline No & 33197 (74.1\%) & 2599 (7.8\%) & $932(2.8 \%)$ & $5987(18.0 \%)$ & $1606(4.8 \%)$ \\
\hline Yes & 11578 (25.9\%) & $1136(9.8 \%)$ & $385(3.3 \%)$ & 1997 (17.3\%) & $568(4.9 \%)$ \\
\hline \multicolumn{6}{|l|}{ Employment status } \\
\hline Employed & 25459 (56.9\%) & 1985 (7.8\%) & $623(2.4 \%)$ & $3807(15.0 \%)$ & $889(3.5 \%)$ \\
\hline Unemployed and seeking work & $1504(3.4 \%)$ & $221(14.7 \%)$ & $101(6.7 \%)$ & $564(37.5 \%)$ & $184(12.2 \%)$ \\
\hline Not working (student/homemaker) & 4625 (10.3\%) & $488(10.6 \%)$ & $153(3.3 \%)$ & $1272(27.5 \%)$ & $392(8.5 \%)$ \\
\hline Unable to work owing to disability & $3124(7.0 \%)$ & 574 (18.4\%) & $287(9.2 \%)$ & $1500(48.0 \%)$ & $556(17.8 \%)$ \\
\hline Retired & $10063(22.5 \%)$ & $468(4.6 \%)$ & $154(1.5 \%)$ & $841(8.4 \%)$ & $153(1.5 \%)$ \\
\hline \multicolumn{6}{|l|}{ Educational attainment } \\
\hline Degrees & 15167 (33.9\%) & 1129 (7.4\%) & 227 (1.5\%) & $2156(14.2 \%)$ & $481(3.2 \%)$ \\
\hline GCSE/A-levels & $26532(59.3 \%)$ & $2379(9.0 \%)$ & $920(3.5 \%)$ & $5198(19.6 \%)$ & $1471(5.5 \%)$ \\
\hline No qualifications & $3076(6.9 \%)$ & 228 (7.4\%) & $171(5.6 \%)$ & $630(20.5 \%)$ & $222(7.2 \%)$ \\
\hline \multicolumn{6}{|l|}{ Income } \\
\hline $\mathrm{N}$-miss & 4635 & 443 & 187 & 872 & 261 \\
\hline$<£ 16000$ & 8324 (20.7\%) & 1039 (12.5\%) & $482(5.8 \%)$ & $2345(28.2 \%)$ & $832(10.0 \%)$ \\
\hline f16 000-29999 & $11165(27.8 \%)$ & $884(7.9 \%)$ & $327(2.9 \%)$ & 1999 (17.9\%) & $483(4.3 \%)$ \\
\hline £30 000-59 999 & $12685(31.6 \%)$ & $867(6.8 \%)$ & $217(1.7 \%)$ & $1828(14.4 \%)$ & 377 (3.0\%) \\
\hline f60 000-89999 & $4794(11.9 \%)$ & $323(6.7 \%)$ & 65 (1.4\%) & $556(11.6 \%)$ & $123(2.6 \%)$ \\
\hline$>£ 90000$ & $3173(7.9 \%)$ & 179 (5.6\%) & $39(1.2 \%)$ & $383(12.1 \%)$ & $97(3.1 \%)$ \\
\hline \multicolumn{6}{|l|}{ Overcrowding } \\
\hline No & 42853 (95.7\%) & 3459 (8.1\%) & $1141(2.7 \%)$ & 7437 (17.4\%) & 1940 (4.5\%) \\
\hline Yes & 1922 (4.3\%) & 276 (14.4\%) & $176(9.1 \%)$ & $546(28.4 \%)$ & $235(12.2 \%)$ \\
\hline \multicolumn{6}{|l|}{ Mental health diagnosis } \\
\hline No & 36018 (80.4\%) & 2341 (6.5\%) & $821(2.3 \%)$ & $4171(11.6 \%)$ & $933(2.6 \%)$ \\
\hline Yes & 8757 (19.6\%) & 1394 (15.9\%) & $496(5.7 \%)$ & $3813(43.5 \%)$ & $1241(14.2 \%)$ \\
\hline \multicolumn{6}{|l|}{ Chronic physical illness } \\
\hline No & $27588(61.6 \%)$ & 2149 (7.8\%) & $724(2.6 \%)$ & $4679(17.0 \%)$ & $1261(4.6 \%)$ \\
\hline Yes & $17187(38.4 \%)$ & $1587(9.2 \%)$ & 593 (3.5\%) & 3305 (19.2\%) & $913(5.3 \%)$ \\
\hline CovID-19 diagnosis & & & & & \\
\hline No & 44577 (99.6\%) & $3701(8.3 \%)$ & $1299(2.9 \%)$ & 7918 (17.8\%) & $2146(4.8 \%)$ \\
\hline Yes & $198(0.4 \%)$ & 35 (17.6\%) & $18(9.0 \%)$ & $66(33.4 \%)$ & $28(14.2 \%)$ \\
\hline Depressive symptoms (PHQ-9) & & & & & \\
\hline Minimal/mild (0-9) & 31585 (70.5\%) & $1444(4.6 \%)$ & $382(1.2 \%)$ & $1870(5.9 \%)$ & $340(1.1 \%)$ \\
\hline Moderate (10-19) & $10510(23.5 \%)$ & $1581(15.0 \%)$ & $613(5.8 \%)$ & 3908 (37.2\%) & 990 (9.4\%) \\
\hline Severe $(20+)$ & $2681(6.0 \%)$ & $710(26.5 \%)$ & $322(12.0 \%)$ & $2205(82.3 \%)$ & $845(31.5 \%)$ \\
\hline Anxiety symptoms (GAD-7) & & & & & \\
\hline Minimal/mild (0-10) & 35440 (79.2\%) & 2035 (5.7\%) & $573(1.6 \%)$ & $3482(9.8 \%)$ & $752(2.1 \%)$ \\
\hline Moderate (11-15) & $5297(11.8 \%)$ & $831(15.7 \%)$ & 378 (7.1\%) & $2080(39.3 \%)$ & $592(11.2 \%)$ \\
\hline Severe (16+) & 4038 (9.0\%) & 870 (21.5\%) & $366(9.1 \%)$ & $2422(60.0 \%)$ & $830(20.5 \%)$ \\
\hline Self-harm/suicidal thoughts & & & & & \\
\hline Yes & 7984 (17.8\%) & 1932 (24.2\%) & 959 (12.0\%) & - & $1978(24.8 \%)$ \\
\hline Self-harm behaviours & & & & & \\
\hline Yes & $2174(4.9 \%)$ & $888(40.8 \%)$ & $718(33.0 \%)$ & $1978(91.0 \%)$ & - \\
\hline Psychological/physical abuse & & & & & \\
\hline Yes & $4121(9.2 \%)$ & _- & _- & $2154(52.3 \%)$ & $1011(24.5 \%)$ \\
\hline Waves of data collection & & & & & \\
\hline Mean (s.d.) & $2.1(1.1)$ & $2.1(1.1)$ & $2.0(1.1)$ & $2.1(1.1)$ & $2.0(1.1)$ \\
\hline Range & $1-5$ & $1-5$ & $1-5$ & $1-5$ & $1-5$ \\
\hline (b) Mental health support strategies & $N=34778)$ & $N=2873$ & $N=898)$ & $N=5881$ & $N=1508$ \\
\hline Formal/structured support & & & & & \\
\hline Taking medication (e.g. anti-depressants) & $5534(15.9 \%)$ & $812(28.3 \%)$ & 309 (34.4\%) & 2157 (36.7\%) & $721(47.8 \%)$ \\
\hline Speaking with a mental health professional & $908(2.6 \%)$ & $197(6.8 \%)$ & $94(10.4 \%)$ & $465(7.9 \%)$ & $219(14.5 \%)$ \\
\hline
\end{tabular}




\begin{tabular}{|c|c|c|c|c|c|}
\hline & Total & $\begin{array}{l}\text { Psychological } \\
\text { abuse }\end{array}$ & $\begin{array}{l}\text { Physical } \\
\text { abuse }\end{array}$ & $\begin{array}{l}\text { Self-harm/suicidal } \\
\text { thoughts }\end{array}$ & $\begin{array}{l}\text { Self-harm } \\
\text { behaviours }\end{array}$ \\
\hline Speaking with a healthcare professional & 495 (1.4\%) & $137(4.8 \%)$ & $72(8.0 \%)$ & $278(4.7 \%)$ & $115(7.7 \%)$ \\
\hline Speaking to somebody on a support helpline & $189(0.5 \%)$ & $60(2.1 \%)$ & $20(2.3 \%)$ & $123(2.1 \%)$ & $69(4.6 \%)$ \\
\hline Online mental health programme (e.g. CBT) & $321(0.9 \%)$ & $62(2.2 \%)$ & $24(2.7 \%)$ & $135(2.3 \%)$ & $60(4.0 \%)$ \\
\hline Any formal/structured support & $6331(18.2 \%)$ & 990 (34.5\%) & 387 (43.1\%) & 2486 (42.3\%) & 858 (56.9\%) \\
\hline \multicolumn{6}{|l|}{ Informal support } \\
\hline Online mental health forum & $321(0.9 \%)$ & $83(2.9 \%)$ & $28(3.1 \%)$ & $182(3.1 \%)$ & $82(5.4 \%)$ \\
\hline $\begin{array}{l}\text { Other mental health resources (e.g. self-help } \\
\text { books, videos, or apps) }\end{array}$ & $1489(4.3 \%)$ & $252(8.8 \%)$ & $70(7.8 \%)$ & 491 (8.3\%) & $160(10.6 \%)$ \\
\hline $\begin{array}{l}\text { Mental health self-care (e.g. mindfulness or } \\
\text { meditation) }\end{array}$ & 7429 (21.4\%) & $882(30.7 \%)$ & 149 (16.6\%) & $1687(28.7 \%)$ & $392(26.0 \%)$ \\
\hline $\begin{array}{l}\text { Speaking about mental health to a friend or } \\
\text { family member }\end{array}$ & $6644(19.1 \%)$ & $821(28.6 \%)$ & 230 (25.7\%) & 1915 (32.6\%) & $522(34.6 \%)$ \\
\hline Any informal support & 10951 (31.5\%) & $1323(46.1 \%)$ & 331 (36.9\%) & $2734(46.5 \%)$ & 723 (48.0\%) \\
\hline
\end{tabular}

themselves at least once since the start of the UK's lockdown. For characteristics, see Table 1 . Around 50\% of participants experiencing psychological or physical abuse had experienced thoughts of suicide or self-harm, and $25 \%$ of them had engaged in self-harm behaviours during the previous week.

Data on mental health support were available for 34778 individuals (Table 1). Around $60 \%$ of participants engaging in self-harm behaviours and $40 \%$ of participants with self-harm/suicidal thoughts or reporting abuse had accessed at least one type of formal or structured mental health support during the first month of lockdown (most commonly psychiatric medications). Almost $50 \%$ of participants in each group had used at least one type of informal mental health support such as talking with a friend or family member Table 1, supplementary Fig. 1).

\section{Discussion}

Notably, the patterning of thoughts and experiences of self-harm and abuse reported during lockdown mirrored usual demographic characteristics, including being higher among younger adults, women, and people experiencing socioeconomic disadvantage, unemployment, disability, chronic physical illnesses and mental disorders. ${ }^{5,7,9}$ The elevated prevalence of abuse and self-harm thoughts/ behaviours in people who had been diagnosed with COVID-19 could indicate a heightened psychological risk during infection, or increased risk of exposure due to either behavioural or occupational factors among individuals already self-harming. Comparisons with usual prevalence levels are challenging given that (i) our sample, though well-stratified and weighted to population proportions, was not random, (ii) underreporting of abuse remains likely, especially if people were living with their abuser during lockdown, (iii) our recruitment strategy involved partnership work with charities representing vulnerable people who may therefore have been more likely to report self-harm or abuse, and (iv) most prevalence data report on levels over a 12-month period or over a lifetime, whereas this study reported on a single month of lockdown. Therefore, the figures presented here are not intended to be accurate estimates of prevalence. Nevertheless, our data suggest that a substantial number of people were affected by these issues during lockdown.

Although $47.8 \%$ of people self-harming had been taking medication, only $14.5 \%$ had spoken with a mental health professional (lower than in previous prevalence studies). ${ }^{3}$ Similarly, only $7.9 \%$ of people experiencing thoughts of self-harm or suicide reported speaking with a mental health professional and $4.7 \%$ with another health professional (lower than the $25.5 \%$ reported in previous prevalence studies). ${ }^{4}$ Speaking with friends or family members was higher in our study (32.6\%) than usually reported $(21.7 \%){ }^{4}$ Levels of formal/structured help-seeking were lowest for people experiencing psychological abuse, and accessing informal support such as speaking with friends or family was lowest among people experiencing physical abuse.

Directly assessing prevalence of abuse, self-harm and thoughts of suicide or self-harm and how these compare with usual levels is challenging during the COVID-19 pandemic. In particular, the results presented in this study do not take into account the frequency or intensity of thoughts and experiences of self-harm and abuse. Further, our abuse measures did not ask about other types of abuse, such as sexual or financial, and numerous other risk factors were not considered. Nevertheless, the data presented here suggest that a substantial number of people experienced difficulties in the first month of lockdown, with fewer than half accessing either formal/structured or informal support. Hence, it is vital that new ways of identifying and evaluating individuals at risk of abuse and self-harm are swiftly rolled-out and additional support is made available to people at home.

Eleonora Iob (D, Department of Behavioural Science and Health, University College London, UK; Andrew Steptoe, Department of Behavioural Science and Health, University College London, UK; Daisy Fancourt (D), Department of Behavioural Science and Health, University College London, UK

Correspondence: Dr Daisy Fancourt. Email: d.fancourt@ucl.ac.uk

First received 1 May 2020, final revision 4 Jun 2020, accepted 9 Jun 2020

\section{Supplementary material}

Supplementary material is available online at https://doi.org/10.1192/bjp.2020.130

\section{Data availability}

Data will be made publicly available following the end of the pandemic.

\section{Acknowledgements}

The researchers are grateful for the support of a number of organisations with their recruitment efforts including: the UK Research and Innovation Mental Health Networks; Find Out Now; 
University College London BioResource; HealthWise Wales; SEO Works; FieldworkHub; and Optimal Workshop.

\section{Author contributions}

E.I., A.S. and D.F. conceived and designed the study. E.I. analysed the data and E.I. and D.F. wrote the first draft. All authors provided critical revisions. All authors read and approved the submitted manuscript. All authors had full access to the data (including statistical reports and tables) in the study and can take responsibility for the integrity of the data and the accuracy of the data analysis.

\section{Funding}

This COVID-19 Social Study was funded by the Nuffield Foundation (WEL/FR-000022583), but the views expressed are those of the authors and not necessarily the Foundation. The study was also supported by the MARCH Mental Health Network, funded by the Cross-Disciplinary Mental Health Network Plus initiative supported by UK Research and Innovation (ES/SO02588/1), and by the Wellcome Trust (221400/Z/20/Z). D.F. was funded by the Wellcome Trust (205407/Z/16/Z). The funders had no final role in the study design; in the collection, analysis and interpretation of data; in the writing of the report; or in the decision to submit the paper for publication. All researchers listed as authors are independent of the funders and all final decisions about the research were taken by the investigators and were unrestricted.

\section{Declaration of interest}

None

ICMJE forms are in the supplementary material, available online at https://doi.org/10.1192/ bjp.2020.130

\section{References}

1 Holmes EA, O'Connor RC, Perry VH, Tracey I, Wessely S, Arseneault L, et al. Multidisciplinary research priorities for the COVID-19 pandemic: a call for action for mental health science. Lancet Psychiatry 2020; 7: 547-60.

2 Wang C, Pan R, Wan X, Tan Y, Xu L, McIntyre RS, et al. A longitudinal study on the mental health of general population during the COVID-19 epidemic in
China. Brain Behav Immun 2020. [Epub ahead of print] 13 Apr 2020. Available from: https://doi.org/10.1016/j.bbi.2020.04.028.

3 McManus S, Gunnell D, Cooper C, Bebbington PE, Howard LM, Brugha T, et al. Prevalence of non-suicidal self-harm and service contact in England, 2000-14: repeated cross-sectional surveys of the general population. Lancet Psychiatry 2019; 6: 573-81.

4 Adult Psychiatric Morbidity Survey: Survey of Mental Health and Wellbeing, England, 2014. NHS Digital, 2016 (https://digital.nhs.uk/data-and-information/ publications/statistical/adult-psychiatric-morbidity-survey/adult-psychiatricmorbidity-survey-survey-of-mental-health-and-wellbeing-england-2014)

5 Domestic Abuse Victim Characteristics, England and Wales: Year Ending March 2019. Office for National Statistics, 2019 (https://www.ons.gov.uk/ peoplepopulationandcommunity/crimeandjustice/articles/domesticabusevictimcharacteristicsenglandandwales/yearendingmarch2019).

6 World Health Organization. COVID-19 and violence against women. What the health sector system can do. WHO, 2020 (https://apps.who.int/iris/bitstream/ handle/10665/331699/WHO-SRH-20.04-eng.pdf?ua=1).

7 Usher K, Bhullar N, Durkin J, Gyamfi N, Jackson D. Family violence and COVID19: increased vulnerability and reduced options for support. Int J Ment Health Nurs [Epub ahead of print] 20 Apr 2020. Available from: https://doi.org/10. 1111/inm.12735.

8 Office for National Statistics. Domestic Abuse Prevalence and Trends, England and Wales: Year Ending March 2019. ONS, 2019 (https://www.ons.gov.uk/ peoplepopulationandcommunity/crimeandjustice/bulletins/domesticabuseinenglandandwalesoverview/november2019).

9 Dalton TR, Knipe D, Feder G, Williams S, Gunnell D, Moran P. Prevalence and correlates of domestic violence among people seeking treatment for selfharm: Data from a regional self-harm register. Emerg Med J 2019; 36: 407-9.

10 McManus S, Lubian K, Bennett C, Turley C, Porter L, Gill V, et al. Suicide and Self-Harm in Britain: Researching Risk and Resilience using UK surveys. NatCen, 2019.

11 Office for National Statistics. Overview of the UK Population: November 2018. ONS, 2018 (https://www.ons.gov.uk/releases/overviewoftheukpopulation november2018)

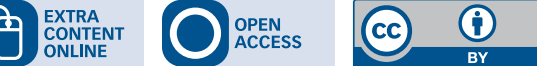

